\title{
Capital Adequacy and its Impact on Banking Liquidity Risk Applied Study in the Bank of the Islamic National and Commercial Iraqi for the Period (2012-2017)
}

\author{
Qassem Ali Omran \\ University of Al - Furat Al - Awsat, Musayab Technical Institute \\ qassem.ali3@yahoo.com
}

Submission date:- 19/8/2018 Acceptance date:- 23/9/2018 Publication date:- 22/1/2019

Keywords: Capital adequacy ,banking liquidity.

\begin{abstract}
The aim of this paper is to highlight one of the risks facing the banking system in general and the Iraqi in particular, both Islamic and commercial, resulting from the low liquidity of banks from their safe levels, which expose the bank to a number of effects, especially when exposed to sudden withdrawals through measuring and analyzing the banking liquidity risk of banking and the statement The most important means used to processing these risks, including the adequacy of capital according to the Basel II Accord. Two banks, the National Islamic Bank and the Commercial Bank of Iraq, were selected and the indicators of liquidity risk were used. Statement of the Effect of the Capital Adequacy Tool as a Tool that Contributes to the Absorption of Banking Risks and their Effects in Mitigating Liquidity Risk The indicators were analyzed and tested by testing F, P-value and impact statement through the R2 parameter using the ANOVA analysis. There is a significant effect of the capital adequacy ratio on the liquidity risk of banks and both banks to varying degrees on the basis of which the alternative hypothesis was accepted. The paper also reached the recommendations of the most important of which is the need to achieve a balance between the size of the balances utilized in the various banking fields and what is maintained, Exceed the capital adequacy ratios for the specified rates by the Central Bank of Iraq.
\end{abstract}

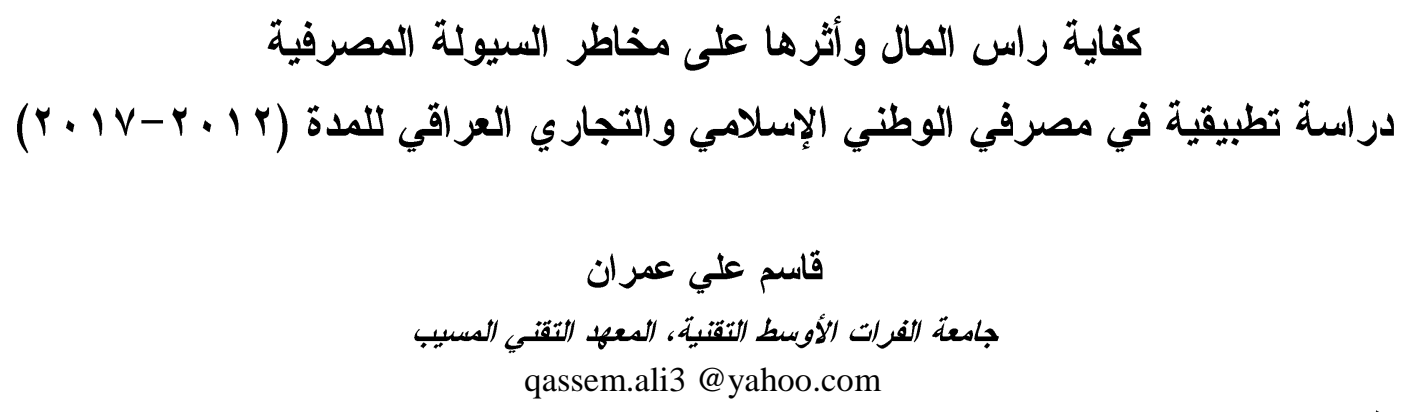

الخلاصة

تهذف هذه الورقة الى تسليط الضوء على احدى المخاطر التي تعرض لها الجهاز المصرفية عامة و العر اقي خاصة بنوعيه الإسلامي والتجــاري

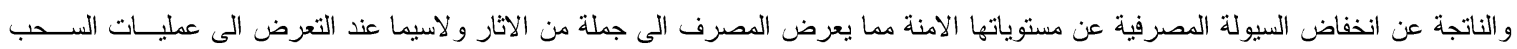

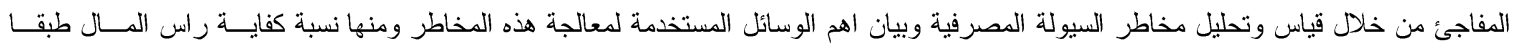

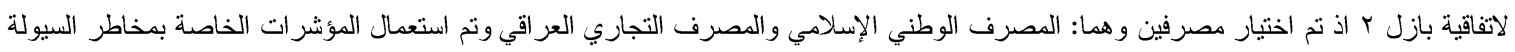

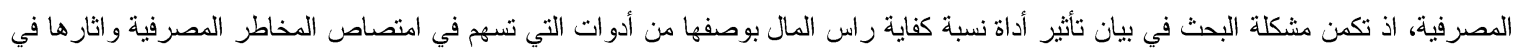

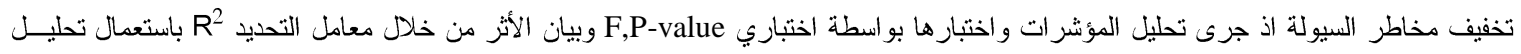

Journal of University of Babylon for Pure and Applied Sciences (JUBAS) by University of Babylon is licened under a Creative

Commons Attribution 4.0 International License. 2018. 


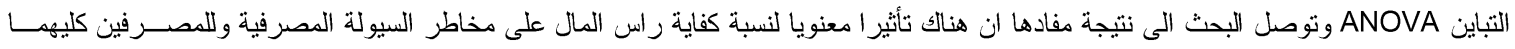

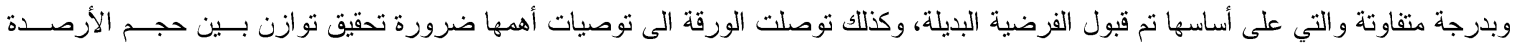

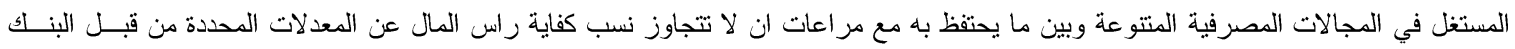

المركزي العراقي.

الكلمات الادالة: كفاية راس المال, مخاطر السيولة المصرفية.

المقدمة

اعدت هذه الدراسة بغية التعرف على حجم مخاطر السيولة المصرفية التي ينعرض لها المصرف الوطني الإسلامي والمصرف التجاري العراقي

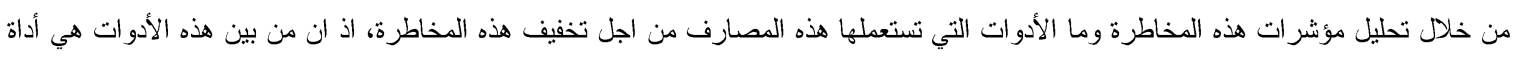
نسبة كفاية راس المال التي حددتها اتفاقية بازل ب و التي تؤكد على استقطاع جزء من راس المال المدفوع و واحتجازه لمو اجهة حالات نقص السيولة وهذه

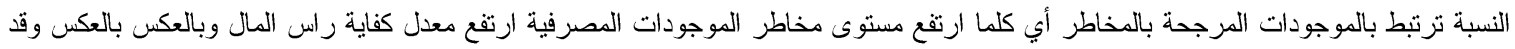

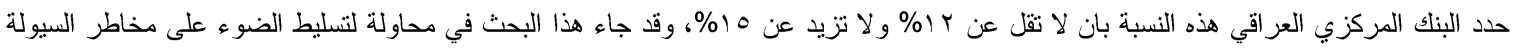
التي تتعرض لها المصارف العر اقية وقياسها وتحليلها وبيان الاثار السليية التي تتركها على مستوى السيولة من خلال توضيح الأثر بين معدل كفاية

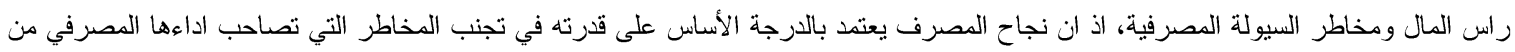
خلال استعمال جملة من الخطط والإجراءات اللازمة التي تخفف من الاثار السلبية لمخاطر السيولة، وقد قسم هذا البحث الى مباحث الأول منهجية البحث، والثاني الجانب النظري، والثالث الجانب التحليلي و الاحصائي، والأخير هو الاستتاجات و التوصيات.

\section{1 - منهجية البحث و الار اسات السابقة}

(1. 1 أشكل البحث

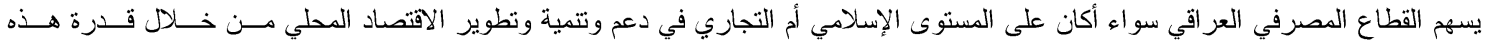

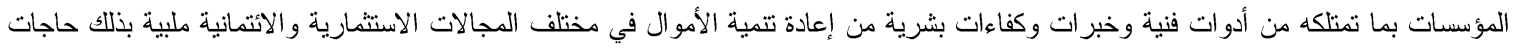

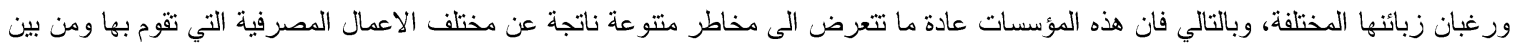

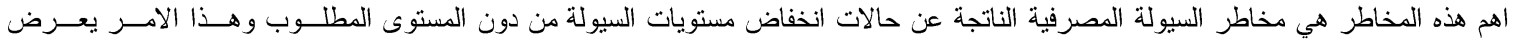

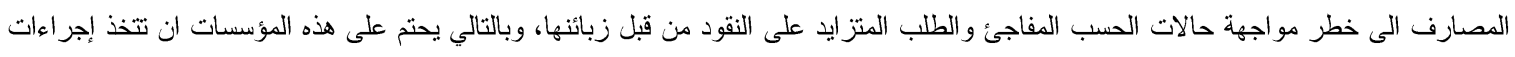

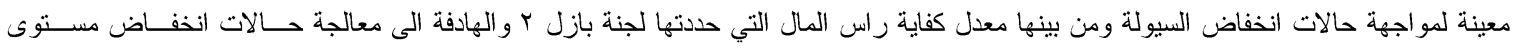

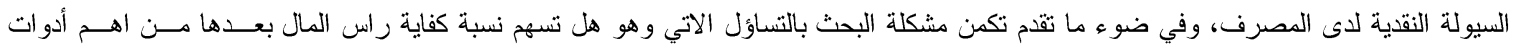

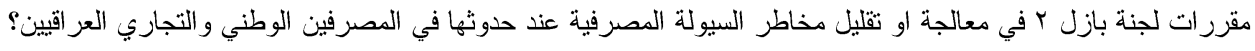

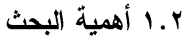
تسعى المصارف العر اقية ولاسيما مصارف عينة البحث الى اتباع أساليب مختلفة لمعالجة مخاطر السيولة المصرفية عند حدوثها سواء كانت هـــه

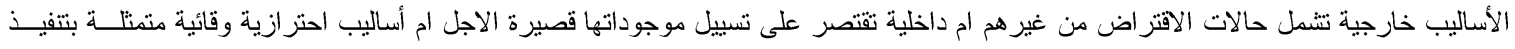

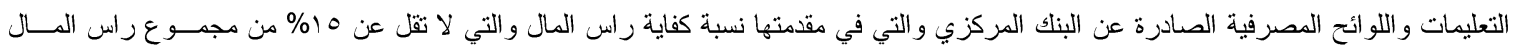

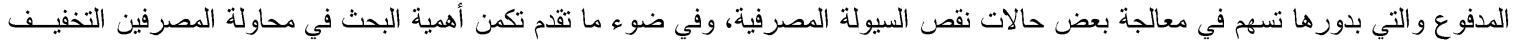

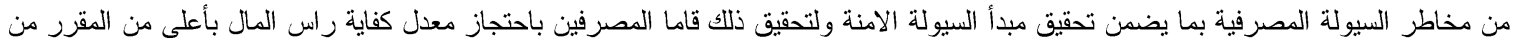

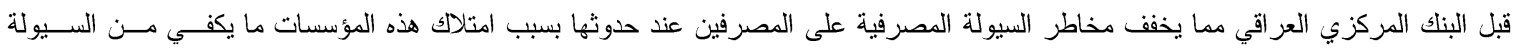
المصرفية. 


$$
\text { يهدف البحث الى تحقيق الاهداف الاتية: }
$$

ا ـ تتاول المرتكزات المعرفية لكل من كفاية راس المال ومخاطر السيولة المصرفية.

r. بيان دور كفاية راس المال في مواجهة مخاطر السيولة المصرفية.

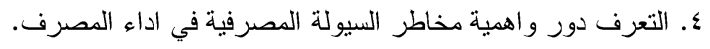

ه. تحليل مؤشرات مخاطر السيولة المصرفية للمصرفين كلاهما.

ج. تحليل العلاقة بين كفاية راس المال ومخاطر السيولة المصرفية.

ع. أمرضية البحث

يقوم البحث على فرضية اساسية وهي:

عدم وجود تأثير معنوي ذي دلالة إحصائية لنسبة كفاية راس المال على مخاطر السيولة المصرفية.

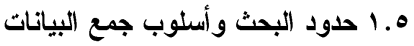

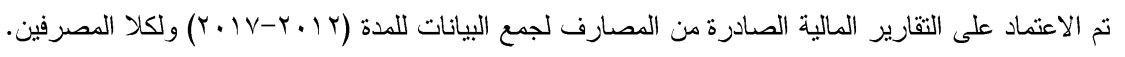

الجدول (1) - الجنغير ات الدر اسة

\begin{tabular}{|c|c|c|c|c|c|}
\hline نوعه & المتغير & نسب المخاطرة المصرفية & نوعه & المتغير & \multirow{4}{*}{ نسبة كفاية راس } \\
\hline معتمد & Y1 & النقدية/الموجودات & \multirow{3}{*}{ مستقل } & \multirow{3}{*}{$\mathbf{x}$} & \\
\hline 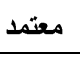 & Y2 & قروض / الودائع & & & \\
\hline معتمد & Y3 & نقد واستثمار ات / الموجودات & & & \\
\hline
\end{tabular}

r - r الار اسات السابقة

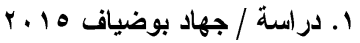

\begin{tabular}{|c|c|}
\hline إدارة مخاطر السيولة في البنوك الإسلامية & عنوان الاراسة \\
\hline 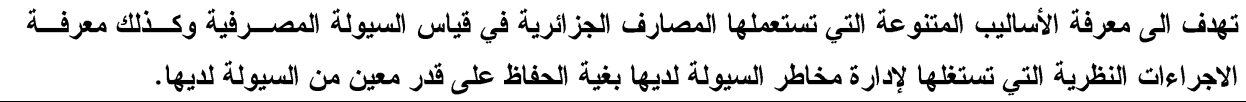 & وصف الار اسة \\
\hline في ظلى على توفى الظروف الأدوات المتو افقة ميع الثريعة الإسلامية تواجه المصارف الاسلامية صعوبة كبيرة فــي ادارة ســيولتها & نتيجة الارساسة \\
\hline
\end{tabular}

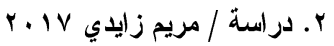

\begin{tabular}{|c|c|}
\hline اتفاقية بازل 3 لقياس كفاية راس المال المصرفية وعلاقتها بإدارة & عنوان الاراسة \\
\hline وكذلت العلاقة بين مخاطر الاراسة الى توضيح كل ما جاءت به اتفاقية بازل ب حول كفاية راس المال المصرفية والمعيار المنبثق عنهـا، & وصف الار اسة \\
\hline 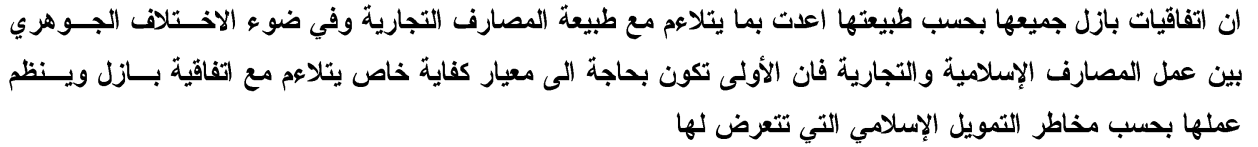 & نتيجة الارساسة \\
\hline
\end{tabular}




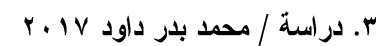

\begin{tabular}{|c|c|}
\hline أثر محددات كفاية رأس المال على أداء المصارف & عنوان الدراسة \\
\hline 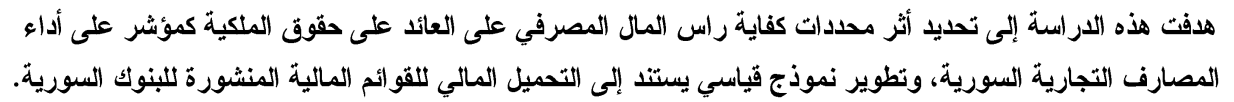 & وصف الدراسة \\
\hline 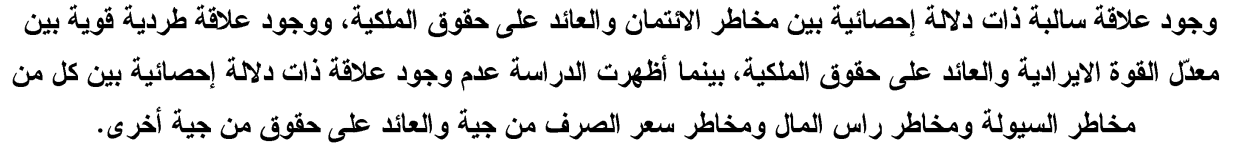 & نتيجة الارسة \\
\hline
\end{tabular}

Mohamed T.Abusharba and others / ع. دراسة

\begin{tabular}{|c|c|}
\hline Determinants of Capital Adequacy Ratio (CAR) in Indonesian Islamic & 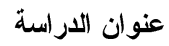 \\
\hline 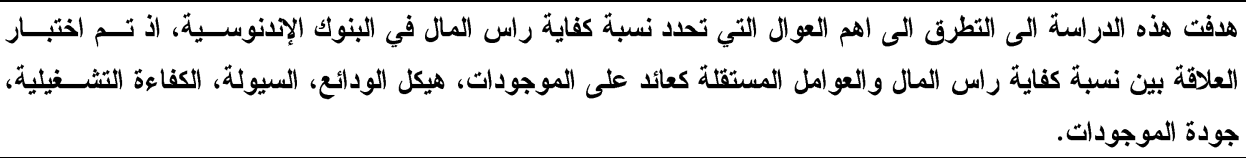 & وصف الار اسة \\
\hline 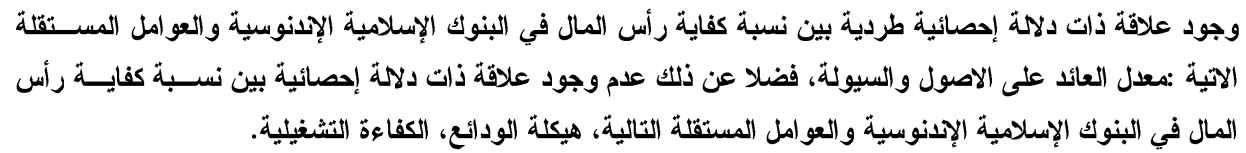 & نتيجة الاراسة \\
\hline
\end{tabular}

و أخير ا فان مساهمة هذه الدر اسة عن الدراسات الأخر بانها تتاولت نسبة كفاية راس المال حسب اتفاقية بازل r كمتغير مستقل ومدى علاقة وتأثيره

$$
\text { على مخاطر السيولة المصرفية وتمت الار اسة على نوعين من المصارف إسلامية وتجارية. }
$$

Y ب الجانب النظري

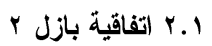

عندما بدأ التفكير في تعديل بازل (1) في نهاية التسعينات استقر الرأي ولاسيما تحت تأثير رئيس اللجة آنذاك (ماكدونا) بان لا يقتصر على مراجعة

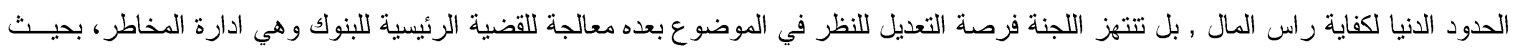

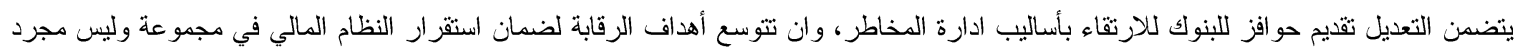

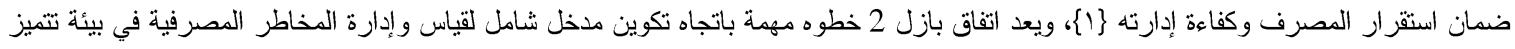

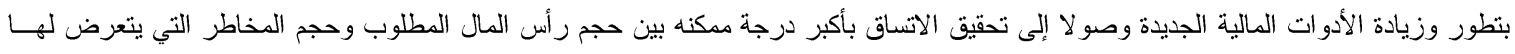

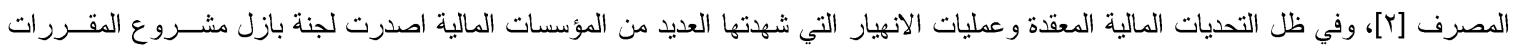

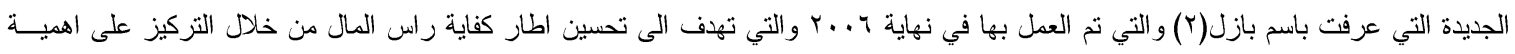

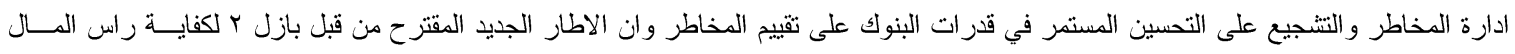

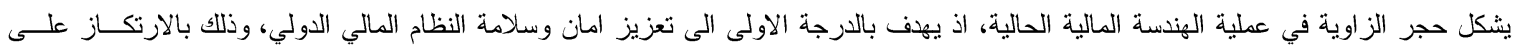

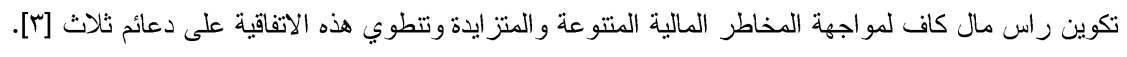




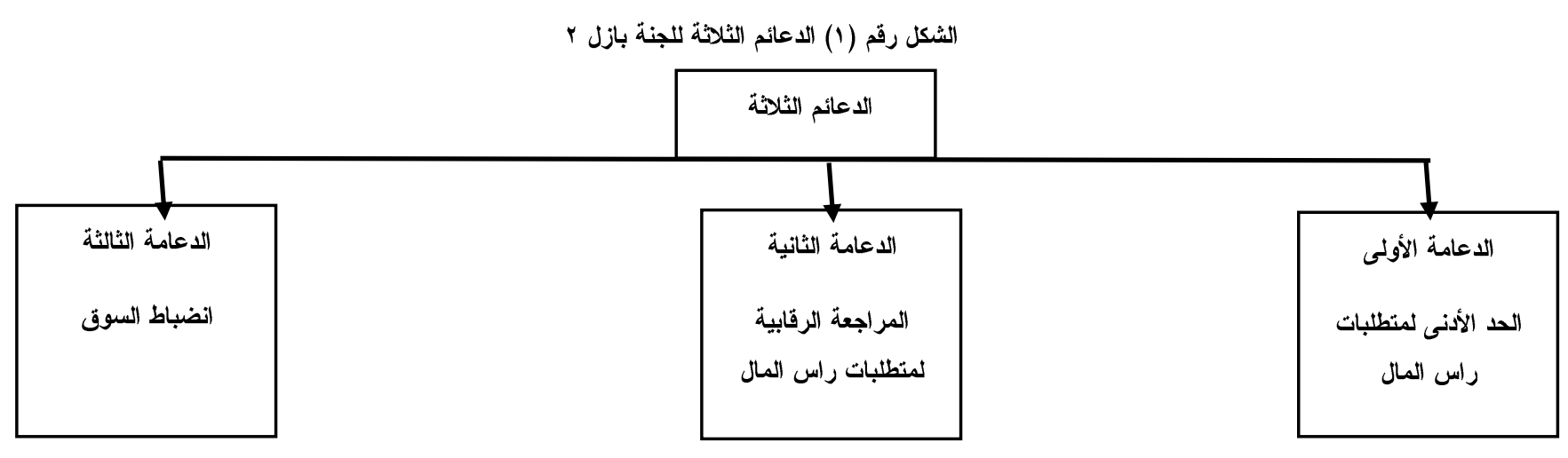

Resource: $\left[{ }^{r}\right.$ ] $]$

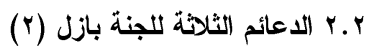
ا. الحد الأدنى لمنطلبات راس المال / يعرض هذا الجزء من الإطار المعدل كيفية حساب الحد الأدنى لمتطلبات راس المال من خلال قسمة راس المال

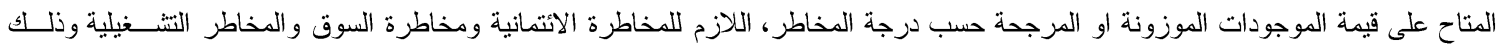

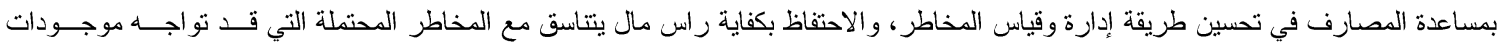

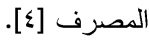

r. عمليات المر اجعة الرقابية / وتقوم على أربعة مبادئ اساسية وهي: (1)

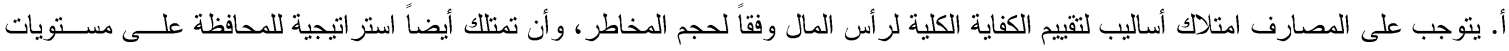
رأس المال المطلوبة. ب. يتوجب على الجهة الرقابية مر اجعة أساليب تقييم كفاية رأس المال لاى المصارف الخاضعة لها، واتخاذ الإجر اءات المناسبة عند قناعتها بعدم كفاية رأس المال الموجود.

ج. يتعين على الجهة الرقابية أن تتوقع احتفاظ المصارف بزيادة في رأس المال عن الحد الأدنى المطلوب، وأن تمتلك هذه الجهة القدرة على إلـز امهم بذلك. د. يتعين على الجهة الرقابية التخخل في وقت مبكر للنع انخفاض أو تراجع رأس المال عن المستوى المطلوب، و اتخاذ إجر اءات سريعة في حال عـدم المحافظة على هذا المستوى. r. انضباط السوق / تهدف الركيزة الثالثة " انضباط السوق "إلى إلزام البنوك بنشر البيانات الخاصة بأساليب تقدير المخاطر وفقا لظروف الأسواق، مما

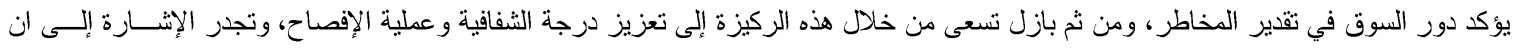

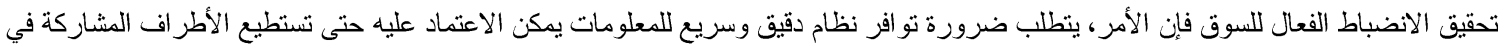
السوق تقييم أداء المؤسسات ومدى كفاءتها ومعرفة مقدرتها على إدارة المخاطر أي التمكن من فهم أفضل للمخاط التي تواجه البنوك ومــدى ملائمسـة

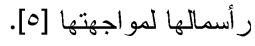

\section{r.r اهداف لجنة بازل(Y)}

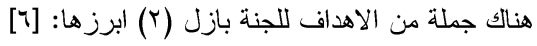
ا. تحقيق المزيد من معدلات الأمان للنظام المصرفي العالمي الجديد. r. إدخال منهج أكثر شمولية لمعالجة الأخطار من خلا لأل أدراج العديد منها و التي لم تكن متضمنة من قبل. ؟. تحسين طرق الإفصاح و الثفافية المتعلقة بالمخاطر ورأس المال. ع. أيجاد تجانس بين رأس المال لدى البنوك وممارسة أدارة المخاطر الحديثة.

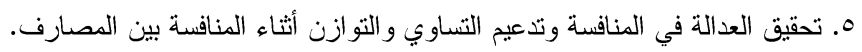


كثير ا ما يستعمل مصطلح كفاية راس المال في العمل المصرفي وفي القو انين و التشريعات الناظمة لعمل المصارف وكذلك في الاتفاقيات الدولية

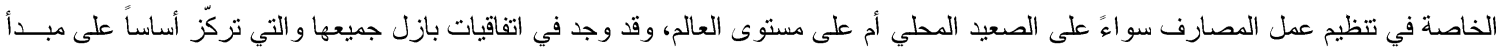

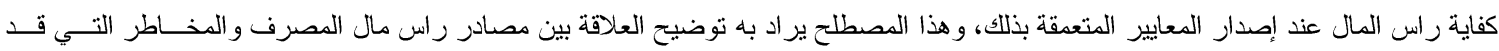

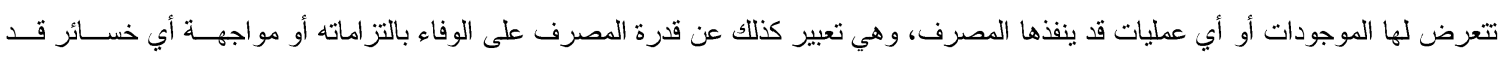
تتعرض لها المصارف[V]، ومعيار كفاية رأس المال هو أحد أهم المعاييز الصادرة عن لجنة بازل (Y) لتتظيم عمل المؤسسات التي تقدم الخدمات المالية

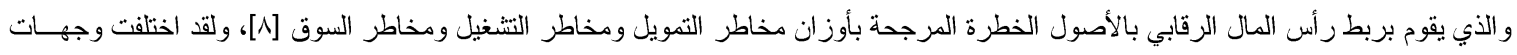

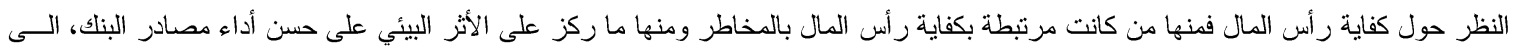

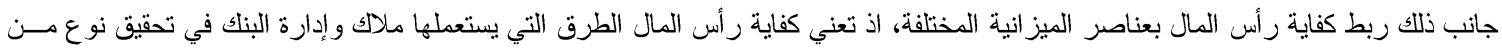

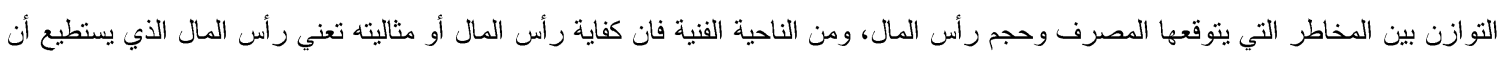

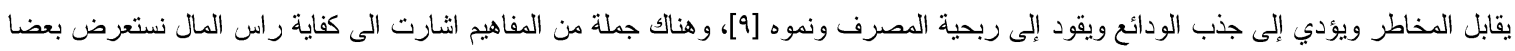
منها فقد عرفت بانها القدرة المالية النهائية للوفاء بالالتزامات التي على المؤسسة المالية أو المصرف التئ ، وهنالك من يطلق على كفاية راس المال بالقدرة

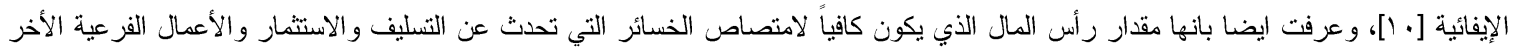
التي تقوم بها المصارف أي باختصار امتصاص مخاطر توظيف الأموال فضلاً عن السماح للمصرف بالاستمرار في عمله [1/])، وعرفها اخرون بانها

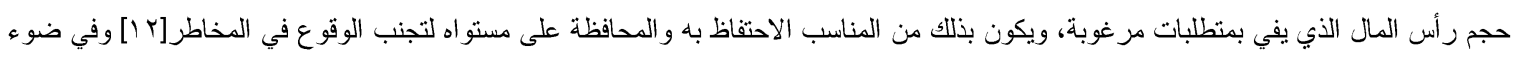

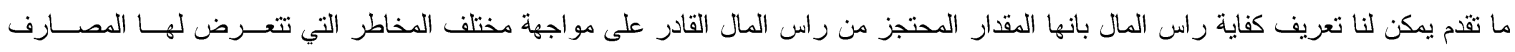
والناتجة عن العمليات الاستثمارية والائمانية.

r.๑

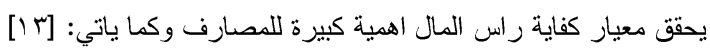

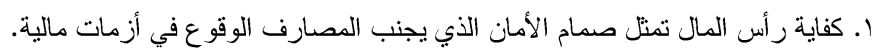

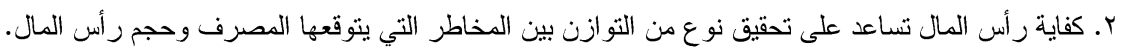

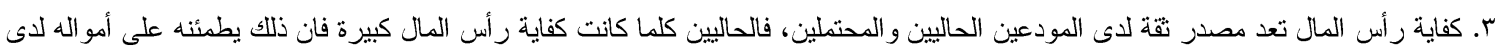

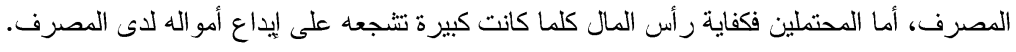

Y. Y r مخاطر السيولة المصرفية تعد السيولة المصرفية و الثبه نقدية من الأهداف الأساسية للمنشآت المالية وخاصة المصارف، وذلك لاحتياجها المستمر الى مستويات محددة من السيولة النقدية لكي تتمكن من الوفاء بالتز اماتها المالية في مو اعيد استحقاقها وتبرز أهمية السيولة للمصارف بشكل عام بشكل كبير خاصة فــي مجــال مو اجهة المسحوبات المستمرة من الودائع ولكي تتمكن من اثثباع حاجات المجتمع من التسهيلات الاثتمانية والاستثمارية بحيث يمكنها من تقديم خدمات

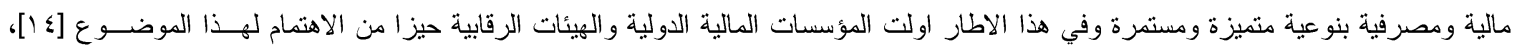

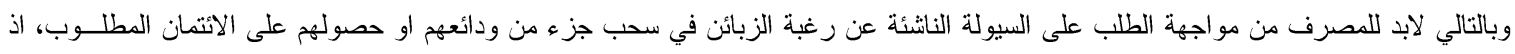

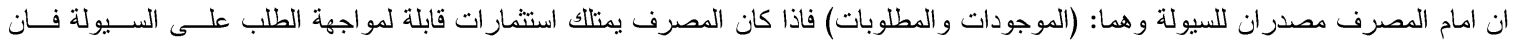

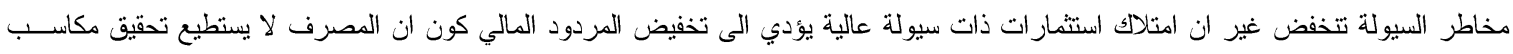

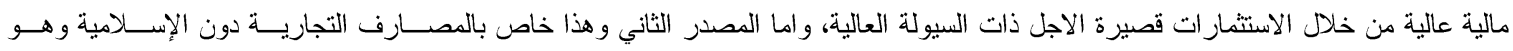

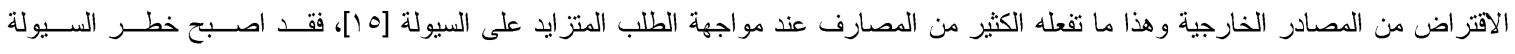

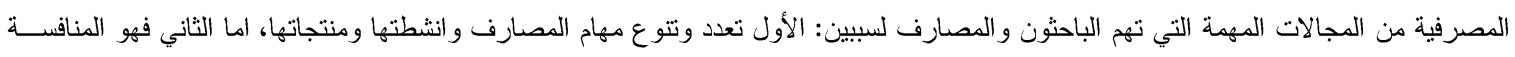
القوية بين المصارف في الحصول على الأموال اللازمة لتمويل مختلف أنشطتها المصرفية، فاذا كانت موجودات المصرف السائلة اكبر من التزاماتــه

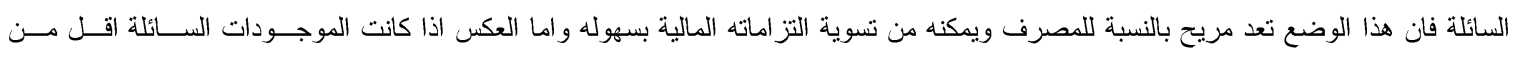

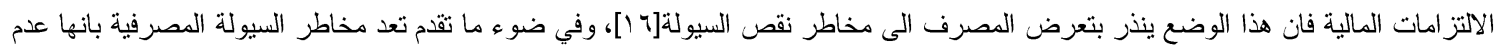

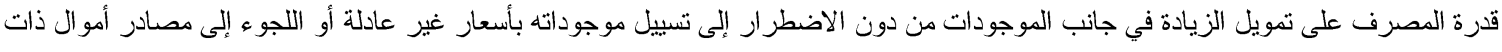

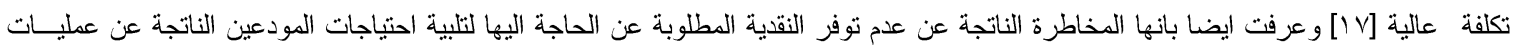

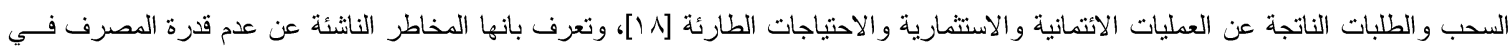


توظيف ما يمتلك من سيولة نقدية في المجالات المناسبة [9 1]، وفي ضوء ما تقدم تتمثل مخاطر السيولة في عدم قدرة البنك في توفير السيولة اللازمــة في الوقت المناسب.

\section{هن أسباب نشوء مخاطر السيولة r.V}

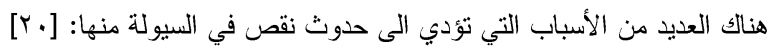

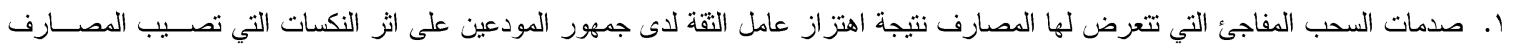
التجارية اثثاء مز اولة أنثطتها الائتمانية والاستثمارية.

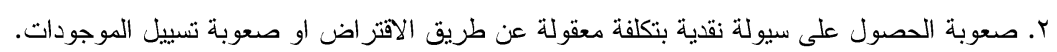
r. رغبة المصارف في الحصول على عو ائد مالية أكبر يدفعها الى الاستثمار في موجودات طويلة الاجل بموارد قصيرة الإنل.

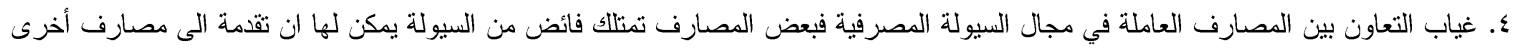
تو اجهه خطر نقص السيولة.

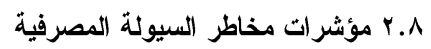

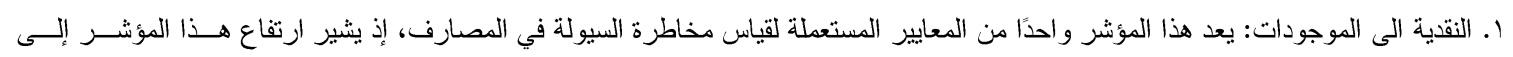

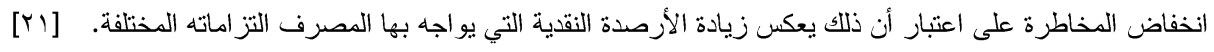

النقدية

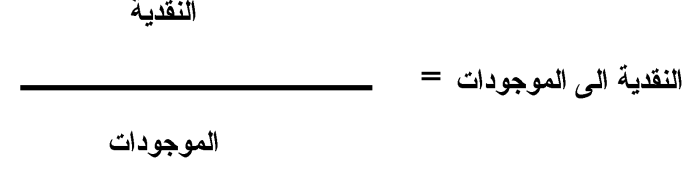

r. النقد والاستثمار ات اللى الموجودات: يعد هذا المؤشر واحدًا من المعايير المستعملة لقياس مخاطرة السيولة في المصارف، إذ يثــير ارتفــاع هـــا

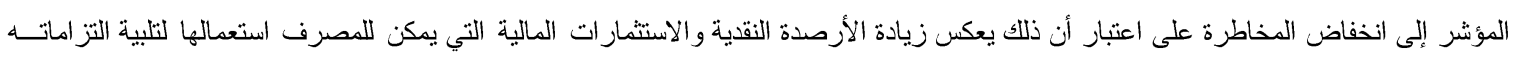

المختلفة. [Yr].

النقد والاستثمار ات

النقد والاستثمارات الى الموجودات =

الموجودات

r. نسبه التوظيف تعكس هذه النسبة مدى قدرة المصرف على توظيف الاموال المتاحة المتحصلة من الودائع لتلبية حاجـات الزبـائن مـن الائتمــان

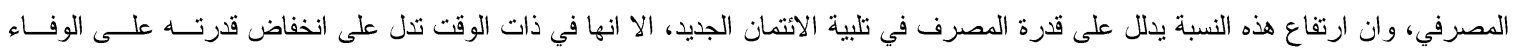

بالتز اماته المالية، وتقاس بتطبيق المعادلة الآتية:23]

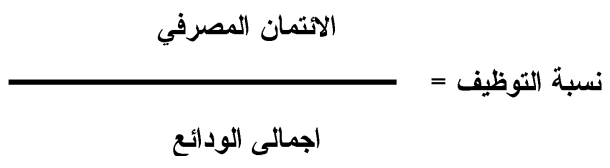




\section{r- الجانب التطبيقي (التحليلي و الاحصائي) ا.ب نبذة تعريفية عن المصارف عينة الاراسة}

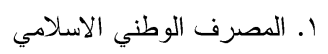

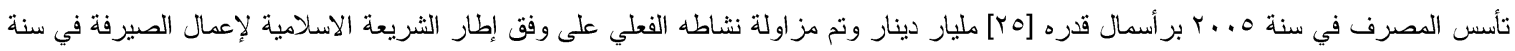

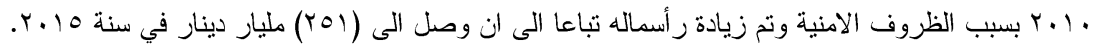

$$
\text { ب. المصرف التجاري العر اقي }
$$

تأسس المصرف في سنة ب99 ا كمصرف تجاري من مصارف القطاع الخاص براس مال قدره (10.) مليون دينار عر اقي وقد حصل علـى إجـازة

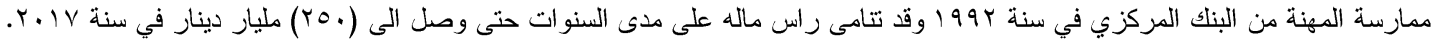

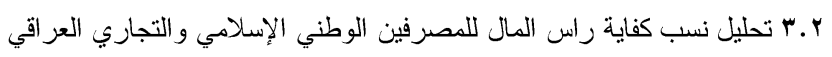

\begin{tabular}{|c|c|c|c|c|c|c|}
\hline$r .1 \mathrm{~V}$ & 5.17 & $r .10$ & $r+1 \varepsilon$ & $r .1 r$ & r. Ir & اسم المصرف \\
\hline$\% r \varepsilon$ & $\%$ \%ч & $\%$ \% & $r \leqslant \%$ & $\mu . \%$ & $17 \%$ & الوطني الاسلامي \\
\hline$\% \diamond 9 . \varepsilon$ & $\% \vee$ \%.^ & $\%$ or. 7 & $\% \vee 7 . . \varepsilon$ & $\% \leq \wedge .9 \vee$ & $\%\{1 . \varepsilon$ & التجاري العراقي \\
\hline
\end{tabular}

\section{الجدول رقم (ץ) نسب كفاية راس المال للمصرفين الوطني الإسلامي و التجاري العراقي}

"المصدر: اعداد الباحث بالاعتماد على البيانات المالية للمصرفين الوطني الإسلامي والتجاري العراقي

من خلال الجدول (Y) و الذي يبين نسب كفاية راس المال للمصرفين (الوطني و التجاري)، اذ ان البنك المركزي يحدد نسبة مئوية من راس المال

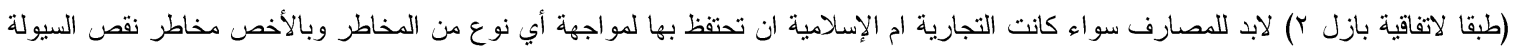

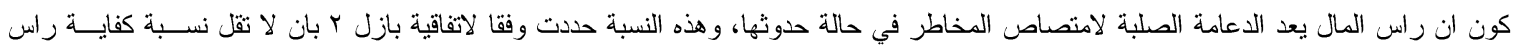

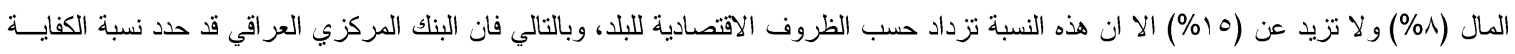

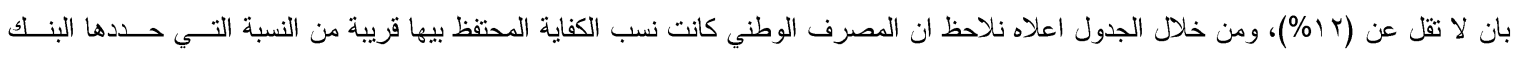

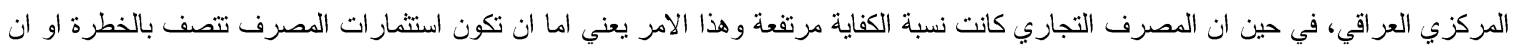
المصرف لدية سيولة فائضة عن الحاجة استغلها في نسبة الكفاية.

\begin{tabular}{|c|c|c|c|c|c|c|c|}
\hline المؤشر العام & Y.IV & $r .17$ & $r .10$ & $r \cdot 1 \varepsilon$ & $r .1 T$ & $r .1 r$ & النسبة \\
\hline$\%$ rr.. & $\%$ Yr.VI & $\%$ rr.lo & $\%$ \% & $\%$ \%. & \%rr.r & $\% \leq 7.9$ & النقدية / الموجودات \\
\hline$\% \backslash \wedge . \neg \wedge$ & $|\leq Y . Y|$ & $\% \backslash\{r . r \mid$ & $\%$ YYY.। & $\% 1 \% 0.7$ & $\% 94 . \wedge$ & $\% \wedge \bullet . ૫$ & الانتمان/ الودائع \\
\hline$\%$ r.०V & $\%$ \%.r & $\%$ r.ro & $\% 1.1$ & $\% 1 . \varepsilon$ & $\% \cdot .9$ & $1.4 \%$ & نقد واستثمار ات/الموجودات \\
\hline
\end{tabular}

r.r تحليل مؤشرات مخاطر السيولة المصرفية للمصرف الوطني الاسلامي

*المصدر: اعداد الباحث بالاعتماد على البيانات المالية للمصرفين الوطني الإسلامي والتجاري العر اقي

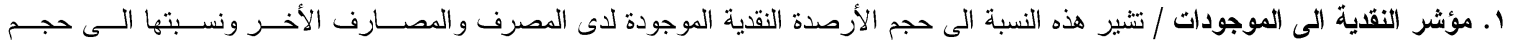
الموجودات الكلية، اذ يعد النقد المحور الرئيس لعمل المصارف لتلبية احتياجاتها سواء كان على مستوى السحوبات الثخصية من قبل الزبائن او تمويل 
المشروعات الاستثمارية، ومن خلال الجدول (؟) في أعلاه نلاحظ ان هناك انخفاضا في هذا المؤشر على مدى السنوات الستة اذ ان اعلى ما وصل الية هذا المؤشر كان في السنة الأولى و اقلها في السنة الأخيرة وهذا الانخفاض يعود الى الارتفاع الحاصل في حجم الموجودات الكلية لدى المصرف الون الوطني

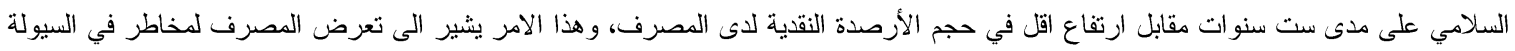

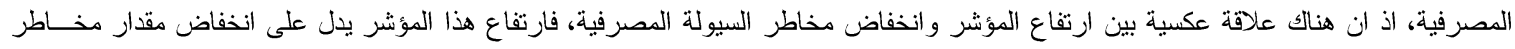

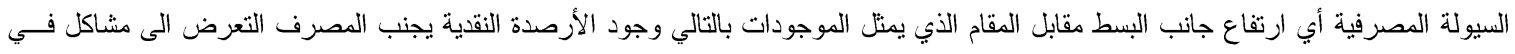

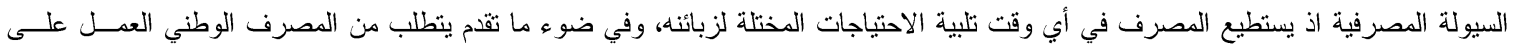

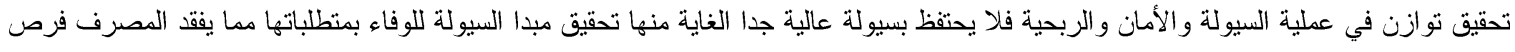

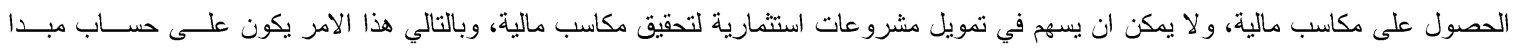

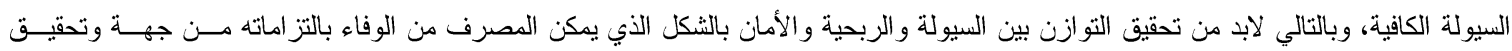

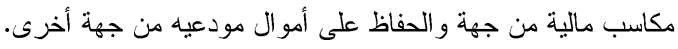

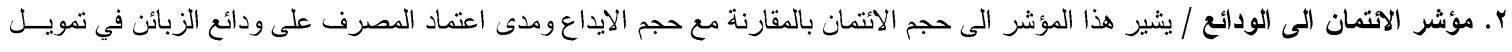

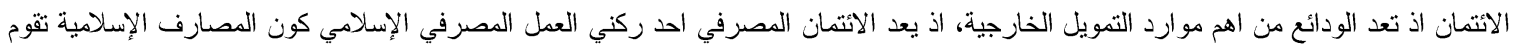

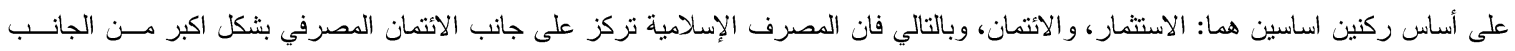

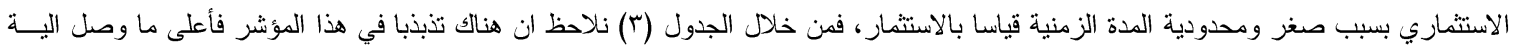

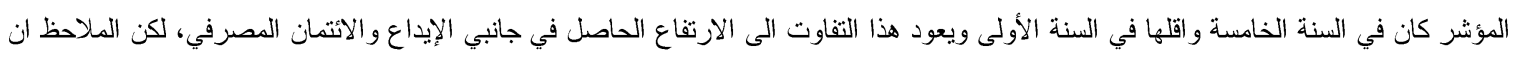

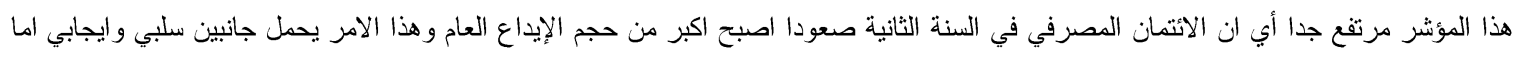

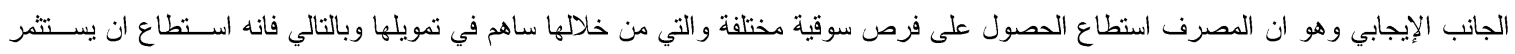

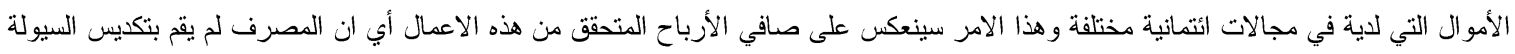

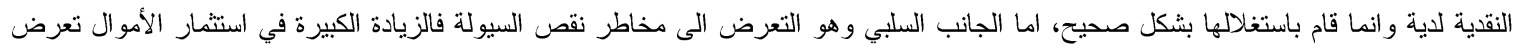

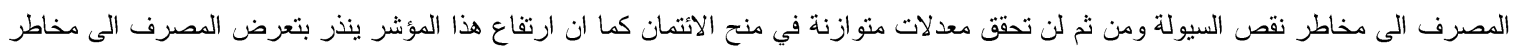

نقص السيولة.

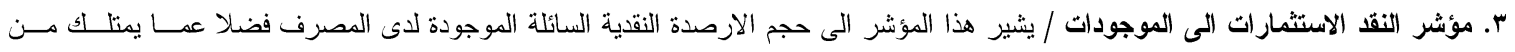
استثمار ات مالية قصيرة الاجل الى حجم الموجودات الكلية، هذا المؤشر يعكس بصورة واضحة إمكانية المصرف في مواجهة أي حالات الانخفاض في

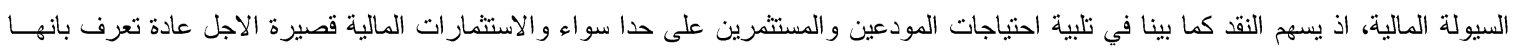
ادوات مالية قصيرة الاجل تمتاز بالسيولة العالية الغاية من الاحتفاظ بها هي مواجهة حالات نقص السيولة لتلافي تعرض المصرف التهات الى مخاطر سيولة،

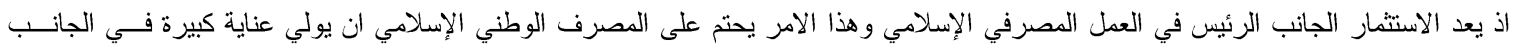

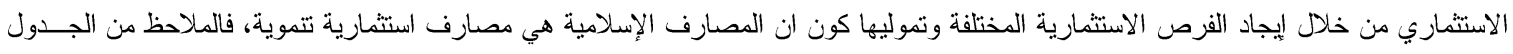

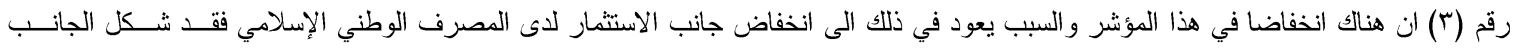

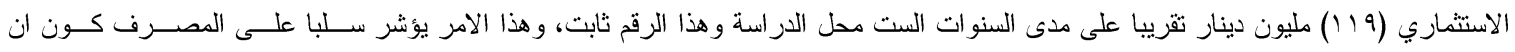

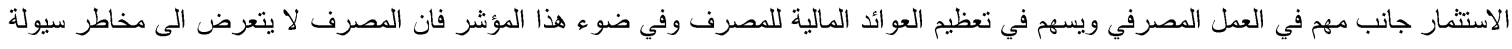

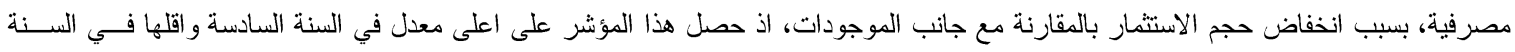

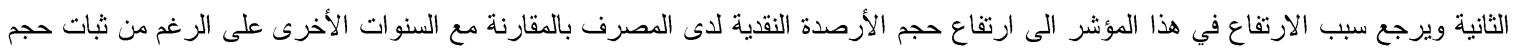

الاستثمار كما بينا سابقا. 
؟ ؟ r تحليل مؤشرات مخاطر السيولة المصرفية للمصرف التجاري العراقي

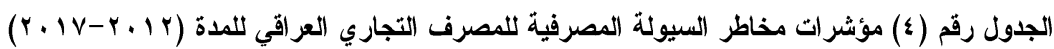

\begin{tabular}{|c|c|c|c|c|c|c|c|}
\hline المؤشر العام & $r .1 V$ & $r .14$ & $r+10$ & $r+1 \varepsilon$ & $r .1 T$ & $r+1 r$ & النسبة \\
\hline \%ro.ro & 11.10 & \%r\&.rv & \%ro.. \& & $\%$ \%५.৭4 & $\% \odot$.rA & $\% \varepsilon 4 . \wedge r$ & النقدية / الموجودات \\
\hline \%т.\& & $\% \wedge . .1$ & \%^.чq & $1 \ldots 1$ & $\% 0.91$ & $\% \varepsilon .9$ & $\%$ \%.. & الاتتمان/ الودائع \\
\hline$\% \diamond \vee . . q$ & $\% \vee \ldots q$ & $\% \vee \ldots . q$ & $\% 04.04$ & \%чs.|T & $\%$ \%.rA & $\%$ \% t.r. & نقد و استثمار ات/الموجودات \\
\hline
\end{tabular}

"المصدر: اعداد الباحث بالاعتماد على البيانات المالية للمصرفين الوطني الإسلامي والتجاري العر اقي

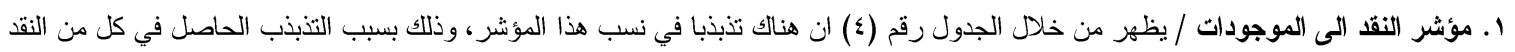

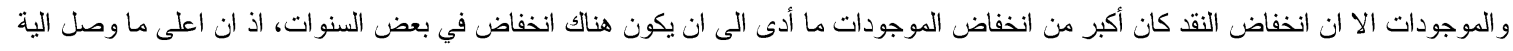

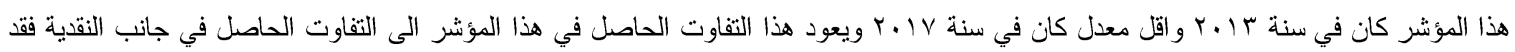

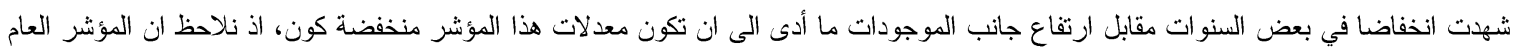

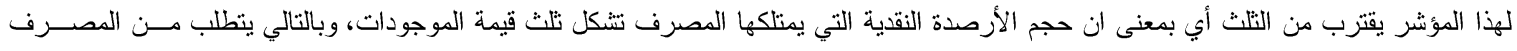

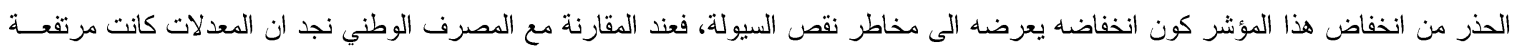

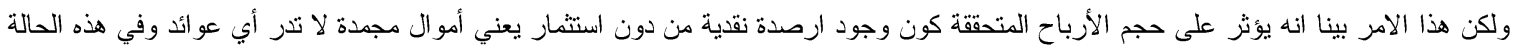

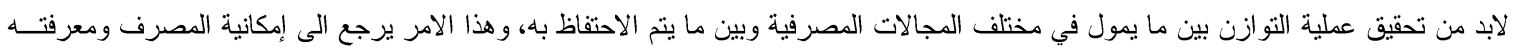

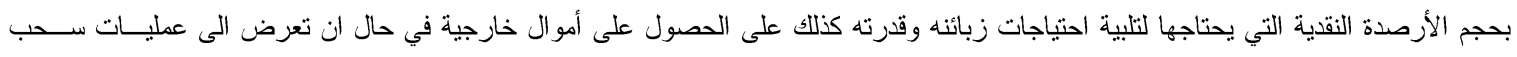

ب. مؤشر الاتتمان الى الودائع / يبين لنا الجدول رقم (؛) ان هذا المؤشر قد حصل على نسب منخفضة جدا عدى السنتين الر ابعة والخامسة التي كانت

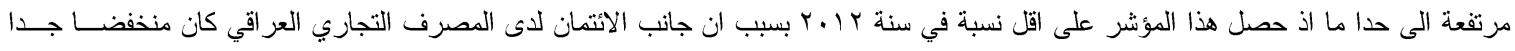

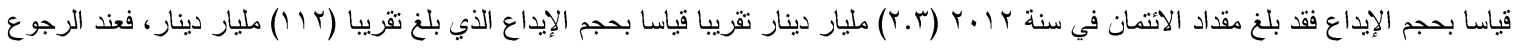

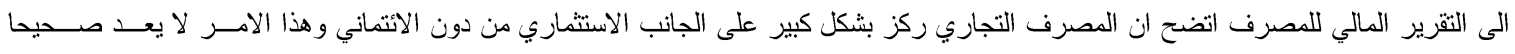

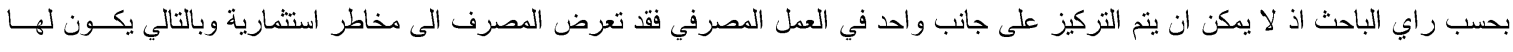

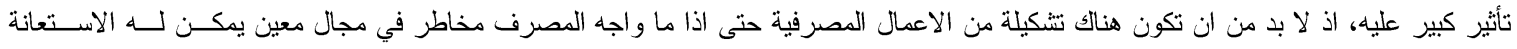

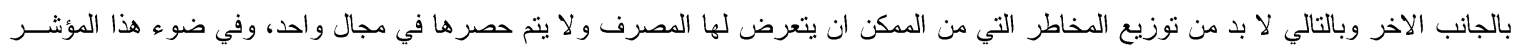

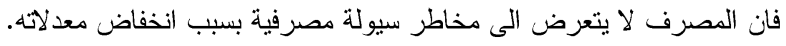

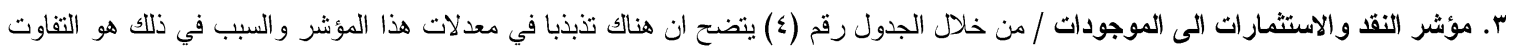

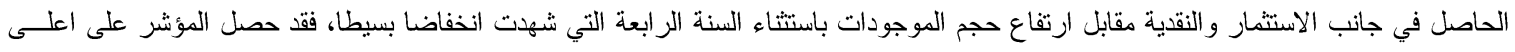

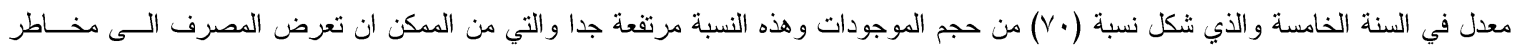

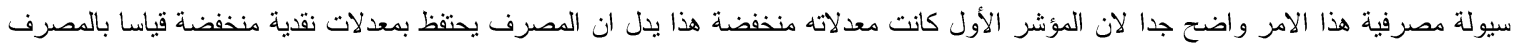

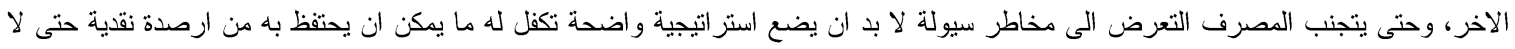
تؤثر على اعماله المصرفية من جهة ولا تعرضه الى مخاطر نقص السيولة من جهة أخرى. 
ه.س الجانب الاحصائي/ (اختبار فرضية البحث)

تحليل تأثير (X) و

أظهرت نتائج التحليل الاحصائي (ANOVA) على ان هناك تأثير اللمتغير المستقل (X) من خلال معامل التحديد

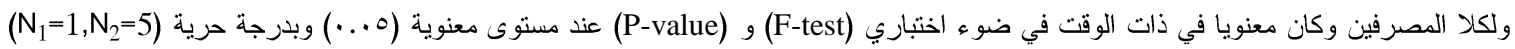

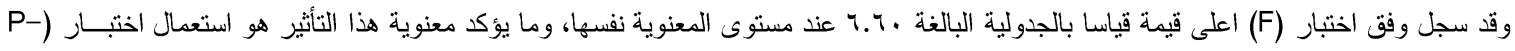

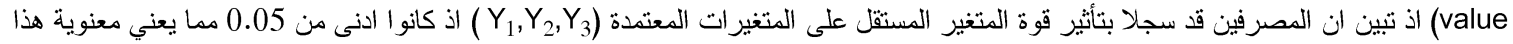

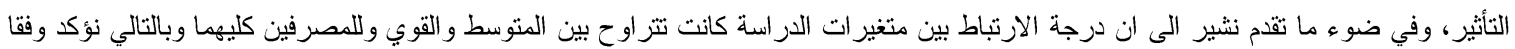
هذه النتائج وفي ضوء الارتباط و المعنوية لمتغير ات الدراسة، اذ يمكن لنسبة كفاية راس المال ان تؤثر على تخفيف مخاطر السيولة المصرفية من خلال

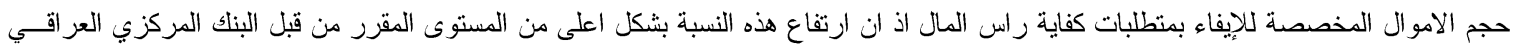
يعني ارتفاع حجم الارصدة النقدية غير المستغلة، وبالتالي فان ذلك ينعكس بشكل مباشر على تخفيض حجم مخاطر السيولة المصرفية التي من الممكن

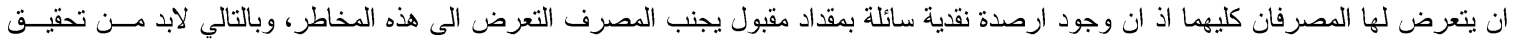
عملية توازن بين حجم الارصدة المالية المتحفظ بيها لغرض الايفاء بمتطلبات كافية والاموال المخصصة للاستتمار في المجالات المختلفة.

\begin{tabular}{|c|c|c|c|c|c|c|c|c|c|}
\hline \multicolumn{10}{|c|}{ الجدول (5) تحليل تأثثير بين (X) و (Y) } \\
\hline \multicolumn{3}{|c|}{ X المتغير المستقل } & \multirow{2}{*}{ المتغير } & \multirow{2}{*}{ 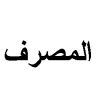 } & \multicolumn{3}{|c|}{ X المتغير المستقل } & \multirow{2}{*}{ المتنغير } & \multirow{2}{*}{ 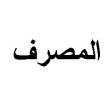 } \\
\hline p-value & F-test & $\mathbf{R}^{2}$ & & & p-value & F-test & $\mathbf{R}^{2}$ & & \\
\hline$\cdots v$ & $11 . \leqslant r$ & or & y1 & \multirow{3}{*}{ العر اقي } & $\cdots \cdots$ & rY.94 & VY & y1 & \multirow{3}{*}{ الإسلامي } \\
\hline$\cdots \cdots$ & $01 . r$ M & N & y2 & & $\cdots \cdots$ & 99.7 & 9 . & y2 & \\
\hline$\ldots \circ$ & 15.09 & 00 & y3 & & $\cdots \cdots$ & $V \vee .19$ & $\wedge \wedge$ & y3 & \\
\hline
\end{tabular}

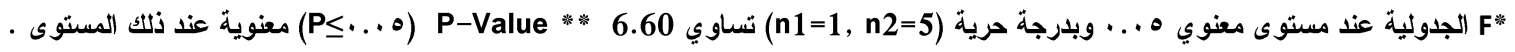
و وهكا في بقية الجداول.

ع - الاستنتاجات و الثوصيات

1. الاستتتاجات

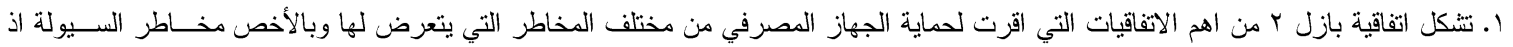

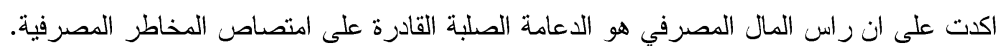

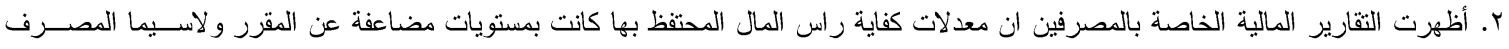
التجاري العر اقي مما يؤشر على ان المصرف لاية استثمار ات مرجحة بمخاطر عدم إمكانية السداد او قد تكون هناك أموال مجمدة.

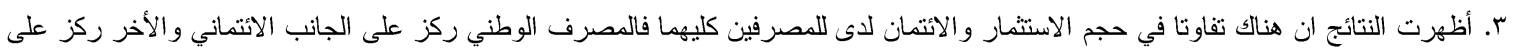
الجانب الاستثماري. ع. أظهرت النتائج ان هناك تفاوتا في مؤشر ات مخاطر السيولة المصرفية للمصرفين كليهما وبسبب التفاوت في جانبي الأتمان والاستثمار اذ ان بعض

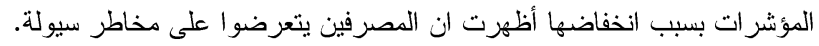

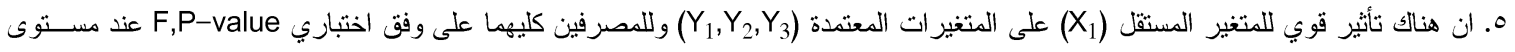
معنوية ه.... هـ 


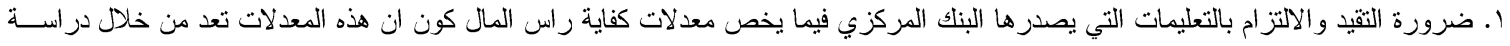

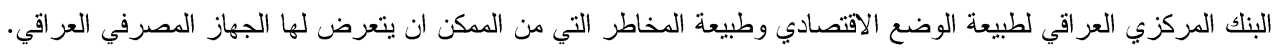

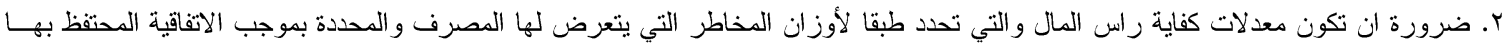

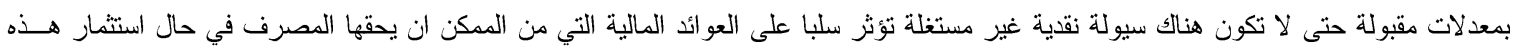

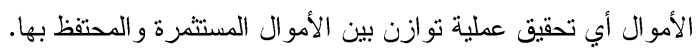
r. ضرورة العمل على تحقيق مبدأ توزيع الاعمال المصرفية بين المجالات الاثتمانية والاستثمارية من دون التركز على جانب من دون الاخر بالثكل

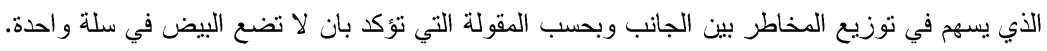

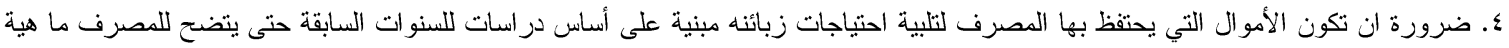
حجم الأمو ال التي يحتفظ بها ليكون في الجانب الامن وان لا يكون هناك فائض في الأمو ال المحتجزة.

\section{CONFLICT OF INTERESTS}

There are no conflicts of interest.

ع. مصبح، حمدي محمد،" واقع تطبيق الجهاز المصرفي الفلسطيني لاتفاقيات بازل وتطور اتها"، رسالة ماجستير مقدمة الى مجلس كلية التجارة، الجامعة

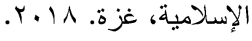

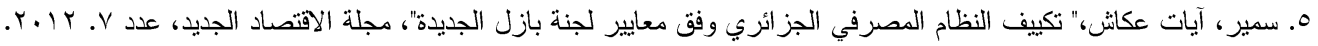

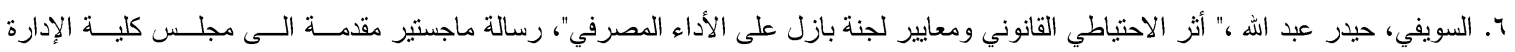
و الاقتصاد، جامعة كربلاء. r ا. r.

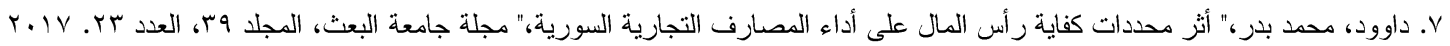

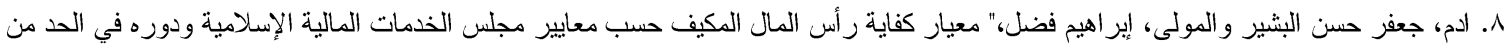

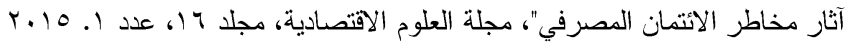
9 . الزغابي، تهاني محمود محمد،" تطوير نموذج لاحتساب كفاية رأس المال للمصارف الإنسلة الإسلامية في إطار مقررات لجنة بازل"، رسالة ماجستير مقدمة

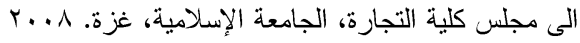
• 1. المولى، رو اء احمد يوسف،" تقييم كفاية رأس المال وفقاً لمتطلبات لجنة بازل ومنظمة التجارة العالمية"، رسالة ماجستير مقدمة الى مجلـس كليــة

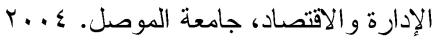
ا ا. المخلافي، عبد العزيز محمد،" تحليل كفاية رأس المال المصرفي وأثزه في المخاطرة والعائد على وفق المعايير الدولية"، أطروحة دكتور اه مقدمة

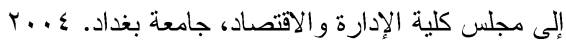
ب ا. المزوري، حسين احمد،" اثر مقررات لجنة بازل المتعلقة بمعيار كفاية رأس المال في توظيف أموال المصارف"، وسالة رسالة مقدمة، مجلس كلية الإدارة

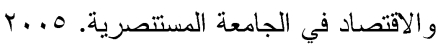

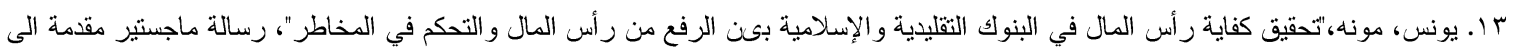

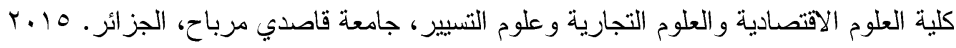

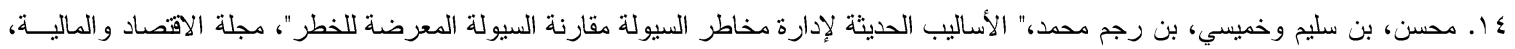

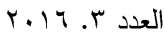
10. احلاسه، نصر رمضان،" دور المعلومات المحاسبية والمالية في إدارة مخاطر السيولة"، رسالة ماجستير مقدمة الى مجلس كلية التجارة، الجامعسـة

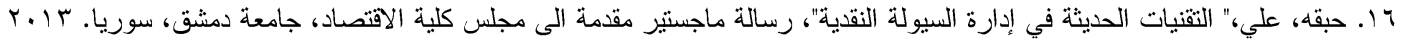

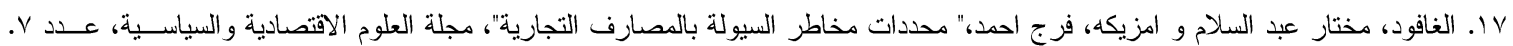




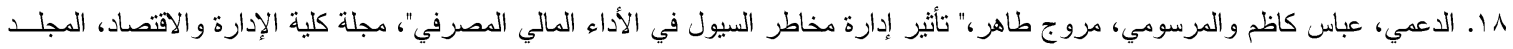

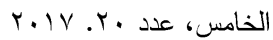

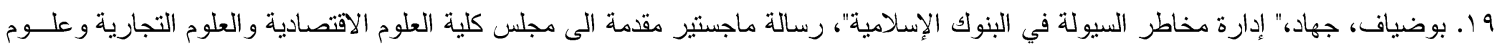

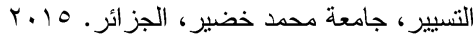
• r. بركاني، سمية،" إدارة مخاطر السيولة وتأثير ها على منح القروض فير في البنوك التجارية"، رسالة ماجستير مقدمة الى مجلس كلية العلوم الاقتصادية

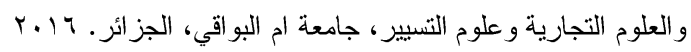

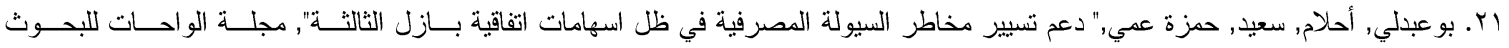

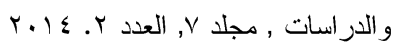
r r. خضيز ، عباس, جاسم, نبر اس," قياس وتحليل معدل العائد و المخاطرة في المصرف التجاري العر اقي", مجلة كلية بغداد للعلوم الاقتصادية الجامعة , عدد ؟

23. Financial Institutions , "New Adequacy Requirements Own Funds (Basel 2)", July-Augus. 2004

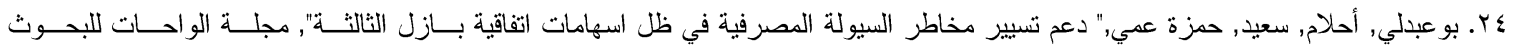

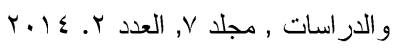

